\title{
Impact of Fiscal Imbalance on Interest Rate in Sri Lanka
}

\author{
A.L. Mohamed Aslam \\ Sri Lanka Planning Service, Ministry of National Policy Planning \\ Sri Lanka \\ E-mail: mohamedaslamalm@gmail.com
}

Keyword: Fiscal imbalance, Interest rate, Money supply, inflation rate and Economy

\begin{abstract}
Interest rate is one of the primary tools in the monetary policy which moves the countries' economy into positive or negative path. In the meantime, the fiscal imbalance keeps a bond on the interest rate of countries. Empirically, this study tested the impact of fiscal imbalance on the interest rate in Sri Lanka using the annual time series data from the period of 1959 to 2014. In this study, the fiscal imbalance was considered as the independent variable and the interest rate was used as the independent variable. While the money supply and the inflation were utilized as controlled variables. To test this impact, the multiple regressions model was employed. Based on the regression outcome, the fiscal imbalance positively impacted on the interest rate at one percent level.
\end{abstract}

\section{Introduction}

What is the fiscal imbalance? The fiscal imbalance means that the fluctuation between government revenue and government expenditure within a financial year which may be surplus or deficit; if it is surplus the government revenue must be greater than government expenditure. On the other hand, if it is deficit, the government revenue must be less than government expenditure. In Sri Lankan experience, the fiscal imbalance is as deficit for long term.

What is the interest rate? Interest rate is the amount of charged, expressed as a percentage of capital by a lender to a borrower for the uses of assets. The interest rates are typically noted on an annual basis, known as the annual percentage rate. The assets borrowed could include the cash, consumer goods, large assets: a vehicle or building. The interest is essentially a rental, or leasing charge to the borrower, for the asset's use. In the case of a large asset, like a vehicle or building, the interest rate is sometimes known as the "lease rate". When the borrower is a low - risk party, they will usually be charged a low interest rate; if the borrower is considered high risk, the interest rate that they are charged will be higher.

The relationship between the fiscal imbalance and the interest rate is complicated which is argued by economist, because the world countries follow the different strategies to solve their fiscal imbalance. [4] states that, In view of classical system components of commodity demand determined interest rate. The behavior of interest in classical system is examined by applying the concept of demand for and supply of loan able funds. Many economists argued that when government finance its deficit by borrowing from the domestic market, loan become scare for privet sector and this activity leads to higher interest and crowding out effect in the economy.

In the world wide, the number of researchers studied the relationship between the fiscal imbalance and the interest rate. But, in this study the following studies had been selected as litterateurs [1-8]. In these studies, the mixed methodologies were employed. Based on the outcomes of these studies, it was confirmed that there was positive relationship between the fiscal imbalance and the interest rate.

In Sri Lankan experience, the relationship between fiscal imbalance and interest rate was not properly studied. This situation formulates a study gap for doing a research on this relationship. Therefore, to fills this research gap this study is designed the following sub items: introduction, research methods, Results and discussion, conclusion and recommendation. 


\section{Research Methods}

Most of the literatures in this study to test the impact of fiscal imbalance on the interest rate were used the following variables such as fiscal imbalance, interest rate, money supply and inflation which were also considered in this study. Here, the interest rate was considered as dependant variable. Likewise the fiscal imbalance, the money supply, and inflation rate were considered as independent variables. The fiscal imbalance was considered as root independent variable and other independent variables were considered as controlled variables. The mathematical relationship between the dependent and independent variables define as follows:

$$
I N T=f(F I, M S, I N F) .
$$

From the mathematical function (1), the econometric equation is derived as:

$$
I N T_{t}=\beta_{0}+\beta_{1} F I_{t}+\beta_{2} M S_{t}+\beta_{3} I N F_{t}+U_{t},
$$

where $I N T_{t}$ was interest rate, $F I_{t}$ defined the fiscal imbalance, $M S_{t}$ illustrated the broad money supply, $I N F_{t}$ demonstrated the inflation rate which was proxied by the Colombo Consumer Price Index, $\beta_{i}$ were the coefficients and $U_{t}$ was error term.

To test the impact of fiscal imbalance in this study, the annual time series data were utilized covering the period of 1959 to 2014 which were gathered from the annual reports of the Central Bank of Sri Lanka. Moreover, the multiple regressions model was used to test the impact of the fiscal imbalance on the interest rate. In the meantime, to test the cointegration order of the variables the Augmented Dickey Fuller (ADF) testing approach was applied. Meanwhile, to confirm the stability of the estimated model the CUSUM plot, R- squared, F- statistic and Durbin Watson statistics were considered, and also to confirm the serial correlation effect of the estimated model the Brush - Godfrey serial correlation test was employed. Moreover, to test the impact of fiscal imbalance in this study the coefficient of fiscal imbalance in the estimated model and its probability value were used.

\section{Results and discussion}

In this study the interest rate, the fiscal imbalance, the money supply and the inflation rate are considered as variables. Here, the fiscal imbalance and the money supply are mentioned in Sri Lankan rupees. Likewise, the inflation rate and the interest rate are indicated in the rate pattern. Following figures show the relationship pattern between the variables and time.

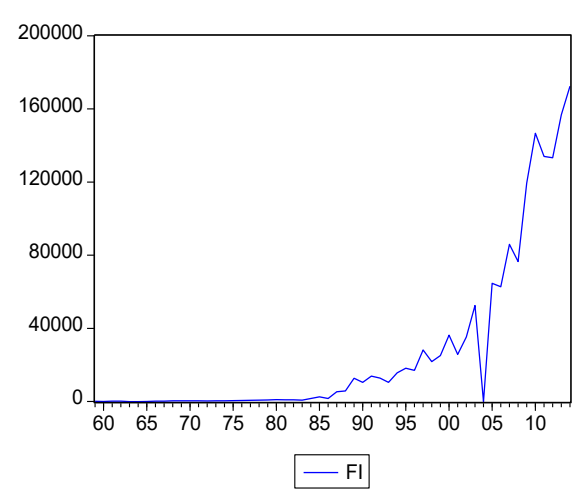

A: Fiscal imbalance

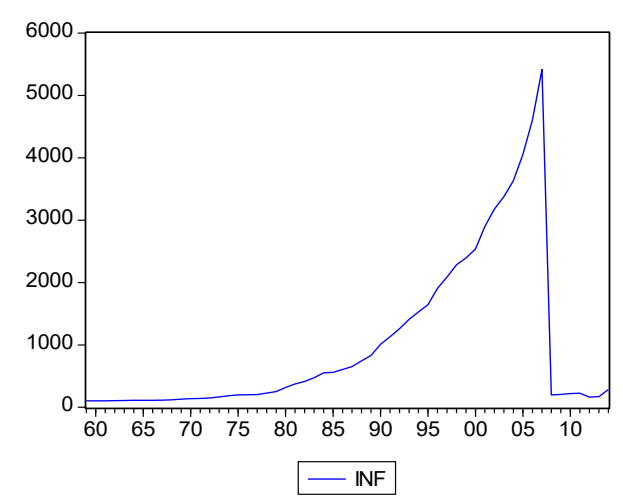

B: Inflation rate 


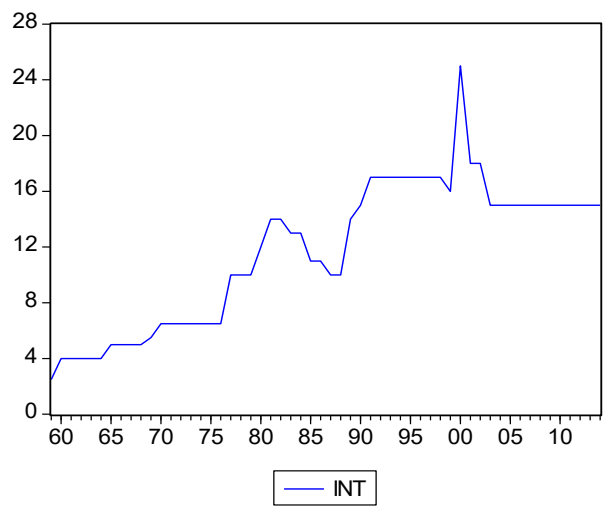

C: Interest rate

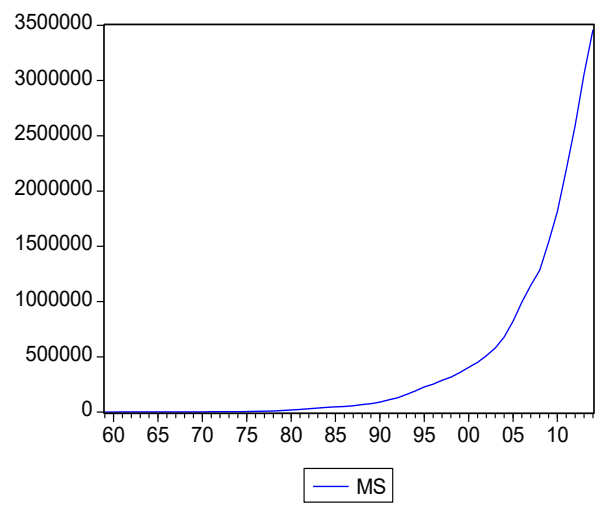

D: Money supply

Figure 1: The trend of variables with time

Based on the figures, all variables in this study show the upward trend with time. However, the money supply steeply goes upward others are not. In this study, to test cointegration order of the variables, the ADF unit root testing approach is used. The following table shows the unit root results of the variables.

Table 1: Unit Root Test Results

\begin{tabular}{|c|c|c|c|c|c|c|}
\hline \multirow[t]{2}{*}{ Variables } & \multicolumn{3}{|c|}{ ADF statistics } & \multicolumn{3}{|c|}{ ADF statistics } \\
\hline & Level & Cri & cal values & $1^{\text {st }}$ difference & & al values \\
\hline \multirow{3}{*}{$I N T_{t}$} & \multirow{3}{*}{-1.547389} & $1 \%$ & -3.557472 & \multirow{3}{*}{-10.31427} & $1 \%$ & -3.557472 \\
\hline & & $5 \%$ & -2.916566 & & $5 \%$ & -2.916566 \\
\hline & & $10 \%$ & -2.596116 & & $10 \%$ & -2.596116 \\
\hline \multirow{3}{*}{$F I_{t}$} & \multirow{3}{*}{3.874936} & $1 \%$ & -3.581152 & \multirow{3}{*}{-10.94762} & $1 \%$ & -3.557472 \\
\hline & & $5 \%$ & -2.926622 & & $5 \%$ & -2.916566 \\
\hline & & $10 \%$ & -2.601424 & & $10 \%$ & -2.596116 \\
\hline \multirow{3}{*}{$M S_{t}$} & \multirow{3}{*}{-0.9228013} & $1 \%$ & -3.584743 & \multirow{3}{*}{4.625698} & $1 \%$ & -3.584743 \\
\hline & & $5 \%$ & -2.928114 & & $5 \%$ & -2.928114 \\
\hline & & $10 \%$ & -2.602225 & & $10 \%$ & -2.602225 \\
\hline \multirow{3}{*}{$I N F_{t}$} & \multirow{3}{*}{-1.970258} & $1 \%$ & 3.581152 & \multirow{3}{*}{-0.894916} & $1 \%$ & 3.581152 \\
\hline & & $5 \%$ & 2.926622 & & $5 \%$ & 2.926622 \\
\hline & & $10 \%$ & 2.601424 & & $10 \%$ & 2.601424 \\
\hline
\end{tabular}

Source: estimated by author

According to the ADF test results, all variables in this study excluding the fiscal imbalance are non stationary at level form because the critical values of the ADF test at whole level greater than the estimated values of ADF test. But in the $1^{\text {st }}$ difference form, all of them excluding the inflation rate are stationary at $1^{\text {st }}$ difference form.

As mentioned in the research method, the multiple regressions model is used to test the impact of fiscal imbalance on the interest rate. For testing the serial correlation effect of the fitted model the Brush - Godfrey serial correlation LM test is used. The following table illustrates the results of the Brush - Godfrey serial correlation LM test.

Table 2: The results of Brush - Godfrey serial correlation LM test

\begin{tabular}{|l|l|l|c|l|}
\hline Model & F- statistic & p- value & Observed R- squared & p-value \\
\hline Log linear model & 0.694240 & 0.504841 & 1.529551 & 0.465438 \\
\hline
\end{tabular}

Source: estimated by author

According to the Brush - Godfrey serial correlation LM test, the estimated model does not suffer from the serial correlation effect. Because, the observed R-squared is 1.529551 and its probability value is 0.465438 . Here, the probability value is greater than at five percent significant 
level. Therefore, the estimated model is not suffering from the serial correlation effect. In the meantime, to test the validity of the estimated model in this study, the CUSUM plot is used which shows as follows.

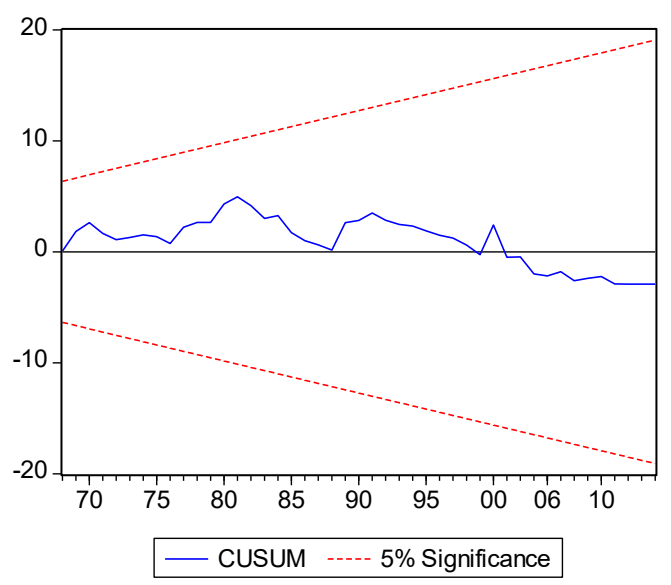

Figure 2: The CUSUM plot of estimated model

In this study, based on Brush - Godfrey serial correlation LM test and the CUSUM plot, the fitted model does not suffer from the serial correlation effect and also which is stable. Therefore, the detail of the fitted model shows in the following table.

Table 3: Results of fitted model

\begin{tabular}{|c|c|c|c|c|}
\hline \multicolumn{5}{|c|}{$\boldsymbol{I N T}_{\boldsymbol{t}}=\mathbf{0 . 9 4 7}+\mathbf{0 . 5 5} \mathbf{F I}_{\boldsymbol{t}}-\mathbf{0 . 1 1} \mathbf{M S} \boldsymbol{S}_{\mathbf{t}}+\mathbf{0 . 0 8 2 I N \boldsymbol { F } _ { \boldsymbol { t } }}$} \\
\hline Variables & Coefficients & Std. Error & t- statistic & p-values \\
\hline $\boldsymbol{C}$ & 0.947407 & 0.188597 & 5.023455 & $0.0000^{*}$ \\
\hline $\boldsymbol{F I}_{\boldsymbol{t}}$ & 0.552011 & 0.103080 & 5.355190 & $0.0000^{*}$ \\
\hline $\boldsymbol{M S}_{\boldsymbol{t}}$ & -0.110111 & 0.047467 & 2.319720 & $0.0246^{* *}$ \\
\hline $\boldsymbol{I N F}_{\boldsymbol{t}}$ & 0.082230 & 0.032175 & 2.555703 & $0.0138^{* *}$ \\
\hline R- squared: 0.866128 & D.W:2.092367 & F- statistic: 105.6735 \\
\hline
\end{tabular}

Source: estimated by author

In the above table 3 , the coefficient of fiscal imbalance is 0.55 and its probability value is less than one percent. Therefore, this variable significantly and positively impacts on the interest rate. It means that when the fiscal imbalance increases by one percent, the interest rate increases 0.55 percents. Meanwhile, when the fiscal imbalance decreases by one percent, the interest rate decreases 0.55 percents. Likewise, the coefficient of money supply in the fitted model is (- 0.11) which negatively impacts on the interest rate at five percent significant level. The inflation rate in the fitted model also positively and significantly impacts on the interest rate at five percent level.

\section{Conclusions and Recommendation}

In this study, to test the impact of fiscal imbalance on interest rate in Sri Lanka the interest rate was considered as dependent variable. Likewise, the fiscal imbalance, money supply, and inflation rate were used as independent variables. In the meantime the multiple regressions model was used to test this impact. Based on the outcome of the fitted model, the fiscal imbalance during the period of 1959 to 2014 in Sri Lanka positively impacted on the interest rate at one percent significant level. 


\section{References}

[1] D. Cohen, O. Granier, The impact of forecasts of budget deficit on interest rates in the United States and other G-7 countries, Federal Reserve board, New York, 1991.

[2] E. Engen, G. Hubbard, Federal Government Debt and Interest rate: American Enterprise Institute, Working paper, Washington DC, No. 105, 2004.

[3] J.C. Odionye, U.K. Ebi, The relationship between budget deficit and interest rate: evidence from Nigeria, European Journal of Business and Social Sciences. 2(1) (2013) 158-167.

[4] M.B. Canzoneri, R.E. Cumby, B.T. Diba, Should the European Central Banka and the Federal Reserve Be Concerned about Fiscal Policy?, Federal Reserve Bank of Kansas City. (2002) 29-31.

[5] M.D. Shapiro, Federal Government Debt and Interest Rates, NEBR macroeconomics Annual. 19 (2004) 148-156.

[6] M.A. Gosselin, R. Lalonde, MUSE: The Bank of Canada's New Projection Model of United States Economy, Bank of Canada Technical Report No. 6, 2005.

[7] T. Laubach, New evidence on the interest rate effects of budget deficit and debt, Board of Governors of the Federal Reserve System, 2003.

[8] Z.Islam et al., Fiscal Imbalance and Interest Rate Change in Pakistan: A Cointegration Analysis, Theoretical Economics Letters. 5 (2015) 616-623. 